\title{
Word Formation Processes of Slang in KasKus
}

\author{
Iqbal Bagaskara Pratama, Ernie Diyahkusumaning Ayu Imperiani \\ Universitas Pendidikan Indonesia \\ Bandung, Indonesia \\ ernie_imperiani@upi.edu
}

\begin{abstract}
The study aims to identify the types of wordformation processes of slang found in KasKus. It also determines the functions of the word-formation processes of the slang. The data are fully collected from kaskus.co.id by observing the post from eight categories, namely: Anime\&Manga Heaven, Computer, Games, Lifestyle, Movies, Music, Otomotif, and Sports which then are transcribed into a table and classified based on the types of word-formation processes using theories proposed by Yule (2010) supported with O'Grady \& Guzman's (1996) as well as Zhou \& Fan's (2013) theory on the functions of slang. The findings show that there are eight types of word-formation processes that formed slang words in KasKus. Borrowing is the most common process with $125(19 \%)$ words, derivation ranks second with 105 (16\%) words, followed by coinage with 89 (13\%) words, clipping with $80(12 \%)$ words, multiple processes with $78(12 \%)$ words, compounding with $75(11 \%)$ words, an acronym with $70(10 \%)$ words, and blending with only $53(8 \%)$ words as the last. Furthermore, there are three functions of the use of slang found in this study, which is: the pursuit of self-identity, emotive feelings of the slang users, and achieving politeness. This study also finds that the way of slang is used depends on the context.
\end{abstract}

Keywords: Kaskus, slang, word-formation processes

\section{INTRODUCTION}

Slang is an informal language that mostly occurs in conversation. Quinn (1999) argues that as in all modern languages, there is a general contrast between formal and informal usage. Burdová (2009) claims that Slang words and expressions are characterized by a high degree of informality, familiarity, vocabulary richness. The fact that language mostly occurs in spoken becomes one of many factors that the high tendency of people using slang language in conversation.

The use of slang in the community has several functions. According to Zhou \& Fan (2013), there are three social functions of slang: Pursuit of Self-Identity, Emotive Feeling of the Slang Users, and Achieving Politeness. The pursuit of Self-Identity means that every community may have different slang which makes the use of slang can be used as the symbol of a community to distinct them from other communities. Emotive Feeling of the Slang Users can be seen in the use of slang that may have the intention of expressing the speaker's attitude towards his/her subject. Achieving Politeness in the use of slang may affect by the notion of politeness, in this aspect the manner.

Slang was mostly used in colloquial speech, mostly spoken than written, and typically restricted to a particular group. There was a definite shortcut. Jones (2006) says that Internet slang is the broad definition given to almost any acronym or abbreviation created to eliminate keystrokes online. There is no set of rules to create internet slang, but the notion of internet slang is to use whatever most convenient way to be able to communicate with others.

One of the internet inventions is social media. Social media is quickly changing communication on a global scale, and it is doing so in incredible ways. The fact that social media has incredibly changed global communication is cannot be predicted. At this stage, slang from a certain group can spread very fast to other community without restriction.

There are many social media platforms in Indonesia, namely Facebook, Twitter, Instagram, Youtube, KasKus, etc. Most of them, however, are not Indonesian-based except KasKus. KasKus is a social media created by the community. It has many distinguish themes, such as games, sports, computers stuff, and so on. KasKus as one of the most popular social media because KasKus has its community unlike other popular social media such as Facebook, Instagram, or Twitter.

There has been a study by Dewi and Rivia (2013) about three processes colloquial words used by teenagers on Facebook. The current research aims to identify the wordformation process of Indonesian internet slang in KasKus in terms of the type of word-formation processes. It also determines the function of the word-formation processes of the slang which is analyzed by using Zhou \& Fan's (2013) theory on functions of slang.

\section{METHOD}

This research was a qualitative research Creswell (2013) because it showed the data by explaining the slang language of word-formation processes found in KasKus.

This research collected the data from 8 KasKus categories namely Anime\&Manga Heaven, Computer Stuff, Lifestyle, Games, Movies, Music, Otomotif, Sports, and Teknik. These categories were chosen considering its theme and popularity with their slang found in the particular theme.

For the limitation of data collection, from the selected categories, the data collection was narrowed down again by choosing 2 to 5 threads of each category with a limitation of 50 pages in total for each category. In total, this research observed 8000 posts.

\section{FINDINGS AND DISCUSSION}

The findings showed that from the 11 types of wordformation processes proposed by Yule (2010), there are 8 of 11 types of word-formation processes that contain slang words on the 8 categories of KasKus. Table I showed that from the 8 types 
of word-formation processes that had slang words, there are 675 slang words found in KasKus.

TABLE I. TYPES OF THE WORD-FORMATION PROCESS

\begin{tabular}{|c|c|c|c|c|c|c|c|c|c|}
\hline \multirow{2}{*}{ No. } & \multirow{2}{*}{ Category } & \multicolumn{8}{|c|}{ Types of Word Formation Process } \\
\hline & & $\overline{\mathrm{AC}}$ & BL & BO & $\mathbf{C L}$ & $\mathbf{C P}$ & $\mathrm{CO}$ & DE & MP \\
\hline $\mathbf{1}$ & Anime\&Manga Heaven & $9(13 \%)$ & $4(8 \%)$ & $24(19 \%)$ & $15(19 \%)$ & $9(12 \%)$ & $12(13 \%)$ & $9(9 \%)$ & $13(17 \%)$ \\
\hline 2 & Computer Stuff & $8(11 \%)$ & $10(19 \%)$ & $15(12 \%)$ & $10(12 \%)$ & $11(15 \%)$ & $9(10 \%)$ & $11(10 \%)$ & $7(9 \%)$ \\
\hline 3 & Games & $19(27 \%)$ & $4(8 \%)$ & $19(15 \%)$ & $17(21 \%)$ & $10(13 \%)$ & $8(9 \%)$ & $12(11 \%)$ & $22(28 \%)$ \\
\hline 4 & Lifestyle & $9(13 \%)$ & $5(9 \%)$ & $15(12 \%)$ & $9(11 \%)$ & $3(4 \%)$ & $10(11 \%)$ & $12(11 \%)$ & $6(8 \%)$ \\
\hline 5 & Movies & $6(9 \%)$ & $8(15 \%)$ & $8(6 \%)$ & $5(6 \%)$ & $2(3 \%)$ & $13(15 \%)$ & $14(13 \%)$ & $5(6 \%)$ \\
\hline 6 & Music & $7(10 \%)$ & $5(9 \%)$ & $9(7 \%)$ & $10(13 \%)$ & $7(9 \%)$ & $14(16 \%)$ & $16(15 \%)$ & $8(10 \%)$ \\
\hline 7 & Otomotif & $6(9 \%)$ & $8(15 \%)$ & $13(10 \%)$ & $6(8 \%)$ & $6(8 \%)$ & $8(9 \%)$ & $17(16 \%)$ & $10(13 \%)$ \\
\hline 8 & Sports & $6(9 \%)$ & $9(17 \%)$ & $22(18 \%)$ & $8(10 \%)$ & $27(36 \%)$ & $15(17 \%)$ & $14(13 \%)$ & $9(12 \%)$ \\
\hline & Total & $70(10 \%)$ & $53(8 \%)$ & $125(19 \%)$ & $80(12 \%)$ & $75(11 \%)$ & $89(13 \%)$ & $105(16 \%)$ & $78(12 \%)$ \\
\hline
\end{tabular}

As Table I showed, Borrowing had the most slang terms found in KasKus with $125(19 \%)$ words, Derivation ranked second with $105(16 \%)$ words, followed by Coinage with 89 (13\%) words, Clipping with 80 (12\%) words, Multiple Processes with 78 (12\% words), Compounding with 75 (11\%) words, Acronym with 70 (10\%) words, and Blending with only $53(8 \%)$ words as the last.

\section{A. Acronym}

There are not many variations of forming new words using acronym because most of the acronym words that were found were also used in several categories. Terms like SS, OOT, BTW, $S R$, and IMO/IMHO were found in most of the categories (which possibly can be found on all categories) because Acronym is one the characteristic of internet slang that is proposed by Jones (2006).

As Table I showed, Games were the most common categories to create slang through acronym. For example the terms FPS, TPS, and RPG which stands for First-Person Shooter, Third-Person Shooter, and Role-Playing Game respectively. These terms are some genres of games. These terms also serve the function of Pursuit Self-Identity (Zhou \& Fan, 2013) as those terms can only be understood by their community.

\section{B. Blending}

Blending is the least process that formed slang terms in KasKus. The result showed that Computer Stuff had the highest number of blending. The terms that were found in the Computer Stuff category are mostly shortened versions of computer stuff, such as mobo (mother + board), inul (install + ulang), and bonek (bottle + neck). These terms are used to minimalize the time used to write down the terms (Jones, 2006), and later on become a habit to the community as a pursuit of self-identity (Zhou \& Fan, 2013)

The blending terms that were found mostly used to minimalize the effort of typing which in line with Jones' notion of internet slang (2006). In addition to that, some of the terms had the purpose of pursuing self-identity (Zhou \& Fan, 2013). This means that the effort of minimalizing typing had the effect of making the shorten terms became a special term that was used in the community that the terms appear.

\section{Borrowing}

The majority of borrowing words in KasKus are coming from the English language. This is because most of the categories observed are using a lot of English terms, such as Anime\&Manga Heaven, Computer Stuff, Games, Lifestyle, Movies, Otomotif, and Sports. However, the borrowing terms are often written down by its pronunciation. For example amajing, trit, laipsekor, tengkyu.

As Table I presented, Anime\&Manga Heaven had the most borrowing terms among other categories. It covered English, Japanese and local languages. The fact that this category discussing Japanese comic and animation made this category contains some of the Japanese slang. For example, the terms moe, chibi, isekai, and harem were quite popular in this category. Moe refers to a young cute innocent and vulnerable fictional female character which perceived as a character that needs protection.

\section{Post 1}

$$
\begin{gathered}
\text { “...btw, gambar azu-nyan nya moe } \\
\text { sekalee...” } \\
\text { “...btw, the azu-nyan picture is veery } \\
\text { moe..." }
\end{gathered}
$$

According to Post 1 , it showed that the term moe has the function to express affection towards the female character. The term moe is only used by anime/manga fans, and the context in this case was used to express the user's affection towards the fictional character. Looking at the context, this term covered two functions, that are pursuit self-identity and emotive feelings (Zhou \& Fan, 2013).

Sports had the second most borrowing terms where most of the borrowing terms were technical terms. However, the borrowing terms were written by its pronunciation, such as: laipsekor, tekel, pinalti, klinikal, klinsit, and hetrik. 


\section{Post 2}

\section{“...cuma bisa cek laipsekor aja karena inet lagi parah hiks..."}

"...i can only check from the laipsekor because the internet is awful :cry:..."

In this post, the borrowing terms were used to express disappointment because the person could not watch the match, he only watched the match through the live score because of the internet problem. This means that this term had the function to show emotive feelings of the user (Zhou \& Fan, 2013).

The least category that had borrowing terms was music. The borrowing terms in this category were mostly used in other categories as well. However, there is a term that was distinctive than any other words, as the Post 3 showed:

Post 3

“...tinggal gitarnya aja mau ganti, yang lama mau dijadiin relic aja..."

"...only the guitar left to be replaced, the used one will become relic ..."

The term relic in this case meant that the old guitar will be completely replaced by the newer one, and it will never be touched again in the future. This showed that the use of the borrowing term in Post 3 were used to express the excitement to change equipment by completely abandoning old equipment. This term also had the function to show emotive feelings of the user (Zhou \& Fan, 2013).

\section{Clipping}

The clipping terms that was found in KasKus were quite various. The clipped form had different vibes from the original form. Terms like gan (juragan), mod (moderator), min (administrator) were use in all categories. These terms used to achieve politeness (Zhou \& Fan, 2013) to express their friendliness.

There was an interesting clipped form found in Kaskus where sub is used in several categories. However, it had at least three different meanings: in Anime \&Manga Heaven and Movie category, the term $s u b$ is a clipped form of subtitle, in Sports category this term is a clipped form of substitution, and Games category this term is a clipped form of subscribe.

Another clipped form that had more than one meaning is mod, a clipped form of moderator and this was used in every category. However, in the games category, the term mod had two meanings. Aside from moderator, the term $\bmod$ was also a clipped form of modding (slang version of modify) used in games where modifying is possible. For example, in a football game, the modder modifies the teams, pitch, and jersey.

Referring to Table I, games had the most clipping forms. Most of the clipped forms were technical terms, such as sub > subscribe, strat > strategy, obs > observer ward, anci > ancient. It can be inferred that the use of clipped form in this category was to shorten keystrokes online (Jones, 2006), and it had the function to pursuit self-identity (Zhou \& Fan, 2013).

\section{E. Compounding}

There were variations of the combination of lexical words that were found in KasKus. The terms were mostly constructed from noun + noun phrase, but there was also verb + noun, noun + verb. The composition of the words also involved in numbers.

According to Table I, sports had the most compounding terms. the compounding terms were formed in many ways. The examples are: masuk goa (verb + noun), liga tendang lari (noun + verb + verb), lapis 2 (noun + noun numbers), and senam jantung (noun + noun). All of these terms changed the entire meaning of its compounded words. As it stated above, masuk goa refers to the fans who did not show up in the forum after their favorite club lost a game.

\section{Post 4}

\section{"Saatnya masuk goa, munyuk yg rapih yah barisnya". \\ "It's time to masuk goa, munyuk please line up neatly"}

The term masuk goa clearly had the purpose to mock the fans whose favorite club lost the game. The fans who are referred (because their team lost) silently agreed because it was like an unwritten ethics that the fans whose their team lost a game do not have the rights to mock other fans in the special thread called Spectre a.k.a Jamban (a special thread where the members are free to mock the football clubs in order to prevent troublemaker in each football club threads). It can be seen that this term is used to pursuit self-identity (Zhou \& Fan, 2013).

Computer Stuff were the second ranked of compounding in terms of frequency where the compounding terms offer different meaning than the compounded words, such as: $k u b u$ merah, kubu biru, rata kanan, and pak tani. Kubu merah and kubu biru refer to two duopoly companies that manufacturing Processor for computer, AMD (red colour) and Intel (blue colour) respectively. Rata kanan means the setting of graphic quality of a game is set to the highest possible and almost all of the game set this option to the right side, while left side are the lowest possible. Pak tani is the most different than others. This term refers to game crackers.

\section{Post 5}

\section{"untuk PES tahun ini kayaknya bakal lama nunggu pak taninya keluar". \\ "for this year PES, it seems that it will take a long time for the pak tani"}

Normally, one game can cost around \$15 - \$75 (Rp. 200.000 - Rp. 1.000.000), and most of Indonesian cannot afford that much money for just a game, so rather than pay that amount of money, they wait for the crack games a.k.a piracy. As the Post 5 revealed, the term pak tani had the function to change the 
mood of the word, rather saying game bajakan (piracy game), it is better to say game pak tani because it collocates with the job of farmer which is plowing (membajak). Therefore, this term had the function of achieving politeness (Zhou \& Fan, 2013).

Another category is otomotif category. Although most of the words found in this category were also used in other categories, such as jaman now, salah kamar, and gaspoll, but this category had a unique word that refer to a condition for a ship in the sea. Post 6

\section{"Karena bahaya bangeet klo ada emak emak yg nyelonong. Langsung oleng kapten tuuh motor klo ga ada ABS."}

\author{
"Because it's very dangerious if there is a \\ crazy mom overtaking. The bike will \\ instantly oleng kapten without ABS"
}

The term oleng kapten was found in a discussion of bike, it means that if the bike sudden braking without using ABS, the wheel will be locked and it causes the bike's steering wheel shaking hard. This is what is meant by oleng kapten. It showed that the function was to show emotive feeling (Zhou \& Fan, 2013) as the user felt worry which caused by other's bad behaviour on the road

\section{F. Coinage}

There were not many coinage terms that originally came from KasKus. This is because there is no strong evidence to proof that there are many words that are coined from KasKus. However, terms like lonje and mastah can be considered as coinage terms that had the function to pursuit self-identity (Zhou \& Fan, 2013). Lonje derrived from English words Lounge which refers to a thread that is purposed to be a place to chit-chat between members that can be found in every category.

According to Table I, Sports were the most common that found coinage terms. Most of the terms, however, were adjectival terms like gacor, tokcer, moncer, greget, jeblok, and bapuk. Some of the terms (gacor, tokcer, moncer) can be considered as synonym.

\section{Post 7}

\section{"jeda internasional, barella makin moncer dengan 2 assist".}

"international break, barella gets more moncer with 2 assists"

From the post 7 above, the term moncer here can be substitute with gacor or tokcer without changing the meaning or the connotation. This showed that the synonym terms in slang may happen, and in this case, all of the synonyms have equal in both meaning and purpose. The function of these terms is to show emotive feelings (Zhou \& Fan, 2013) as the users used the term moncer to show happiness because the football player played well.

The coinage terms that were found in KasKus mostly used in most of others social media as well. In addition to that, most of the term had the functions of showing emotive feelings (Zhou \& Fan, 2013). In other words, coinage was the popular process that formed slangs in the form of adjectives and adverbs.

\section{G. Derrivation}

There were many variations of how slang formed in derivation process. Some of it using symbol to substitute "nya" with apostrophe (") and "x" like ceritax and kaya'a. Other derivation that was substitute is the reduplication. The reduplication words often substitute with " 2 " or double apostrophe (") like ngos 2 an, ogah"an, ngomong 2 so it changed the reduplication into suffix form.

Post 8

\section{"Kata orang bijak sih ngapain bergantung sama tim laen $n$ washit?" \\ "Wise people said that why depends on other teams and washit?',}

As Post 8 stated, the term washit here was only added a single letter, but the connotation changed. The term itself is derision to referee because the community believes that the referee was bribed so he often making unfair calls in the match. It can be seen that this term was used to show distrust towards referee, thus, this slang term had the function to show emotive feelings of the users as well the opposite of achieving politeness (Zhou \& Fan, 2013)

There were some interesting uses of using slang terms in otomotif category. Terms like nyicip and minang were used to something that related to automotive. Nyicip refers to "taste" the feel of a vehicle, it means how does it feel to drive/ride the vehicle, while minang refers to purchase the vehicle.

\section{H. Multiple Processes}

The findings showed that the processes that were combined mostly includes the borrowing process. This is in line with the popularity of the slang terms that using borrowing as the common process. Terms like triple A, VACation, low bajet, moefikasi were the examples of how borrowing affecting the other process. Triple A is a combination of compounding + borrowing + acronym. This refers to a high-quality game because to play the game, it requires high spec computer. VACation is the combination of acronym + blending + borrowing (VAC + vacation). VAC is the abbreviation of Valve Anti-Cheat (a system to ban people who use illegal software). Post 9

"happy VACation deh buat yg nyoba".

"happy VACation for them who tried" 
The term VACation here used to indicate people that got banned from the system because they tried to use cheats (although in the post there were no record yet). Thus, this term had the function to pursuit self-identity (Zhou \& Fan, 2013).

Referring to Table I, Games had the most Multiple Processes to form slang terms. Most of the terms were technical terms that can be found on several games. For example, cliff farming was used in game Dota 2. It refers to the way of killing monsters in a cliff which makes the monster couldn't attack back. Another term like farming simulator refers to a player (same game) who always killing monster without participating in clash (player vs player) which could cost the game. These two terms had the functions of showing user's feelings as well as to pursuit self-identity (Zhou \& Fan, 2013).

\section{CONCLUSION}

There were eight types of word-formation processes that formed slang words. Borrowing was the most common process while Blending was least common. Two categories were common to form slang through the word-formation process, Sports and Games. The least category to form slang was Movies. The majority of the words were used to pursuit self-identity. It can be inferred that there is a fusion between two communities.
Lastly, the use of slang language to achieve politeness were largely used in question and answer thread.

Slang found in KasKus were mostly found in light context. It means the context does not need a deep explanation. This gives a new insight that even in an environment where language can be used freely, particularly in the social media environment, the use of language is still bound with the context.

\section{REFERENCES}

Burdová, V. (2009). Student slang. Masaryk University in Brno.

Creswell, J. (2003). Qualitative inquiry and research design. Thousand Oaks, California: SAGE Publications, Inc.

Dewi, H., \& Rivia, D. (2013). Word-formation of colloquial words in Facebook created by Indonesian teenagers. English Language and Literature Journal, 1(1), 1-10.

Jones, R. (2006). Internet slang dictionary. S. L.: Lulu Sales Rank.

O'Grady, W., \& Guzman, V. (1996). Contemporary linguistics analysis: An introduction. Boston: Addison Wesley Pub Limited.

Quinn, G. (1999). The learner's dictionary of today's Indonesian. Allen \& Unwin.

Yule, G. (2010). The study of language ( $4^{\text {th }}$ Edn.). Cambridge: Cambridge University Press

Zhou, Y., \& Fan, Y. (2013). A sociolinguistic study of American slang. Theory and Practice in Language Studies, 3(12), 2209-2213. doi: 10.4304/tpls.3.12.2209-2213 